\title{
Palm Creases Analysis in Students and Staff of a Teaching Hospital in Kathmandu
}

\section{Nirju Ranjit', Bidur Adhikari', Rajani Shrestha', Anusuya Shrestha', Rosha Bhandari', Deepesh Dhungel ${ }^{2}$ and Jyoti Gautam ${ }^{1}$}

${ }^{1}$ Department of Anatomy, Maharajgunj Medical Campus, Maharajgunj, Kathmandu, Nepal

2Department of Anatomy, Gandaki Medical College, Pokhara, Nepal

\begin{abstract}
Introduction: Palm creases have been studied for a long time and have been recently found to be helpful in tracking underlying medical and genetic conditions. Scientific study and typing of palm prints have been found to be lacking in the Nepalese population

Methods: A cross sectional study was done on 252 subjects, 153 male and 99 female, from Kathmandu, Nepal. Subjects were selected by purposive sampling from different age groups. Demographic profile including age, sex, and handedness was collected. Palm print pattern was recorded by digital photography. Each photograph was analysed visually by single observer and pattern of palm crease was noted. Variation of each crease was also noted.

Results: On the basis of relation between radial longitudinal crease and proximal transverse crease, $17.3 \%$ subjects had open type of palm crease which was significantly more in females while $76.6 \%$ subjects had closed type crease which was significantly more in males. Meeting type of palm crease was found in $5.7 \%$ of subjects. On the basis of relation between proximal and distal transverse crease, normal crease type was found in $90.1 \%$ of subjects, Simian type was found in $7.7 \%$ subjects and Sydney type was found in $1.4 \%$ of subjects. The concordance of this pattern in left and right palms was found statistically significant.

Conclusions: This study presented data from 252 seemingly normal healthy subjects and found that most of them had the normal with no branching, that is normal 1 and closed crease types. Most of the individual major creases were seen to be branched type.
\end{abstract}

Keywords: crease; palm; Simian; Sydney

Correspondence: Ranjit Nirju, Department of Anatomy, Maharajgunj Medical Campus, Maharajgunj, Kathmandu, Nepal. Email: nirju073@gmail.com

DOI: $10.3126 / \mathrm{mj}$ sbh.v18i1.21039

Submitted on: 2018-09-09

Accepted on: 2018-11-28 


\section{INTRODUCTION}

The hairless thick skin of palm shows epidermal friction ridges, also called papillary ridges, and flexure lines, which are larger. The latter form the major and minor palm creases. While papillary ridges are parts of outlines of squames, flexure lines are formed by attachment of skin to deep fascia around synovial joints. ${ }^{1}$ The human palm has three major creases: radial longitudinal crease, proximal transverse crease towards the radial side and distal transverse crease towards the ulnar side. A single transverse crease running from the radial to ulnar sides, representing fused transverse creases is called a Simian crease. ${ }^{2,3}$

Recent advances have led to biometric examination of people for identification, some of which rely on finger prints and palm prints can be used for the same. ${ }^{4-7}$ Pattern of palm creases can give clues to underlying clinical conditions including dental conditions and chromosomal aberrations. ${ }^{8-16}$ Palm prints also serve as surface markings to deeper structures in the hand. ${ }^{17}$ Palm prints have intrigued people for a long time and have been studied for typing characters as in traditional palmistry too.

Palm creases have been analysed and studied subjectively as well as objectively. ${ }^{3,18,19}$ In the Nepalese population, no such study has come to the researcher's attention despite rigorous literature search. The general characteristics of palm creases in this population is largely unknown. The study aims at analysing the patterns of palm creases in a small group of Nepalese people.

\section{METHODS}

Morphological analysis of 252 pairs of palm creases, 153 males and 99 females from subjects of age over 18 years, selected by convenience sampling was carried out. A cross-sectional study was done from January 2016 to November 2016. Ethical approval was obtained from the

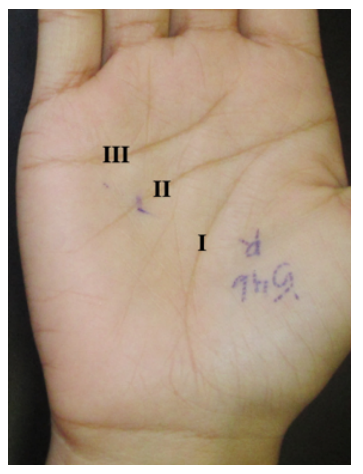

Fig 1. Major palm creases

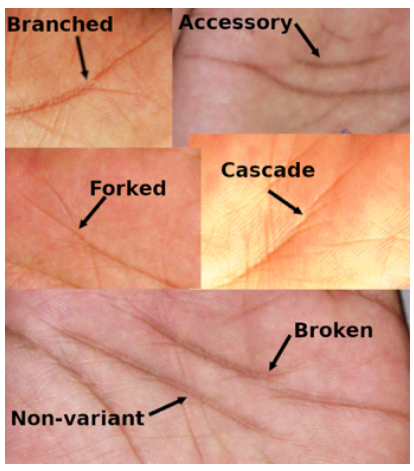

Fig 2. Types of individual major crease
Institutional Review Board. The exclusion criteria were deformed hands and blurry or unidentifiable photographs. Written informed consent was taken from all subjects before photography.

Each case was allotted a code that was written on the palm before photography. All unedited photographs of palms were observed. Major palm creases were identified as radial longitudinal crease, proximal transverse crease, and distal transverse crease. These were numbered I, II and III respectively (Fig 1).

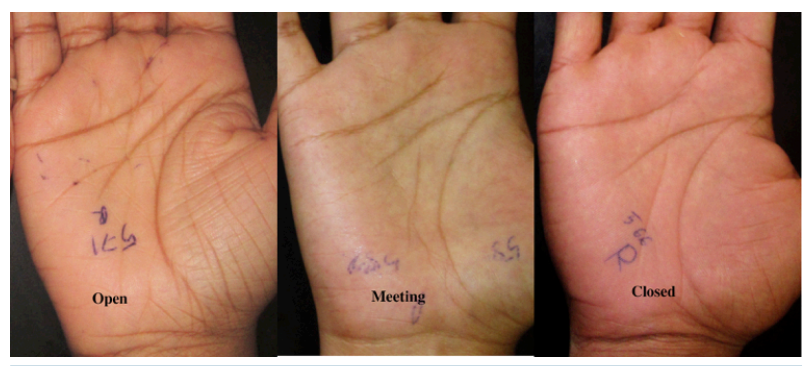

Fig 3. Palm crease types according to relation between I and II

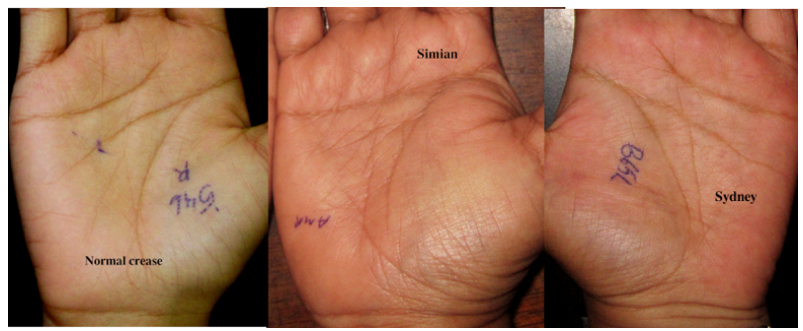

Fig 4. Palm crease types according to relation between II and III 
They were further classified as non-variant, branched, forked, broken, accessory and cascade (Fig 2). Palm creases were classified as open, closed or meeting according to the relation between I and II (Fig 3), and as normal crease, Simian and Sydney crease according to the relation between II and III (Fig 4).

Sub types of normal creases, Simian and Sydney creases were identified according to variations of II and III based on the methods of Park et al. (2010). ${ }^{3}$ In normal 1 crease type, II and III don't meet. In normal 2, II and III meet by recurrent branches. In Simian 1, branch of II and III don't exist. In Simian 2, proximal branch of II exists. In Simian 3, distal branch of III exists. In Simian 4, proximal branch of II and distal branch of III exist. In Simian 5, II and III meet by branches. In Sydney 1, no branching exists in II and III. In Sydney 2, proximal branch of II exists. In Sydney 3, distal branch of III exists. In Sydney 4, proximal branch of II and distal branch of III exist. In Sydney 5, II and accessory III meet by branches. In Sydney 6, II and accessory III meet by recurrent branches. These types are illustrated in fig 5 . Those prints that did not fit any definite group were considered "unknown" type.

Data was entered in epidata version 1.3 and analysed in SPSS version 17. Descriptive analysis of frequencies was done. Comparison between sides and comparison between male and female creases was done using Freeman Hilton extension of Fisher exact test. $\mathrm{P}$ value $<0.05$ was considered statistically significant. In this study, the relationships between palm creases have been identified into objective categories and branches and variations of each crease has been identified.

\section{RESULTS}

The study was done among 252 subjects. 153 $(60.7 \%)$ of the subjects were males and $99(39.3 \%)$ were females. Table 1 shows prevalence of palm crease types based on the relation of crease I and II. The type of palm creases on both sides were associated to each other while the type of only the
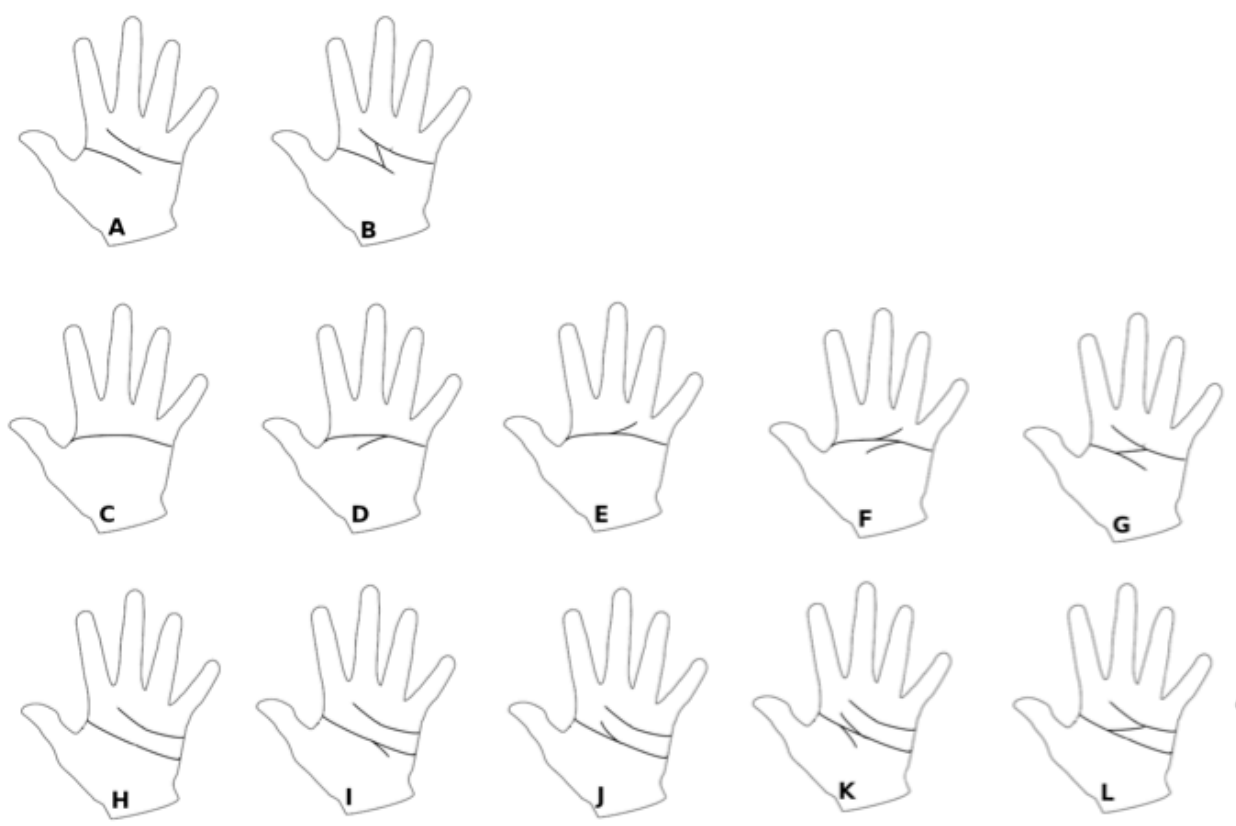

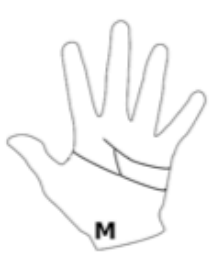

Fig 5. Subtypes of normal crease, Simian and Sydney crease. A: Normal 1, B: Normal 2, C: Simian 1, D: Simian 2, E: Simian 3, F: Simian 4, G: Simian 5, H: Sydney 1, I: Sydney 2, J: Sydney 3, K: Sydney 4, L: Sydney 5, M: Sydney 6 
Table 1. Prevalence of open, closed and meeting crease types

\begin{tabular}{|l|l|l|l|l|l|}
\hline \multicolumn{2}{c}{ Right } & \multicolumn{1}{c}{ Left } & \multicolumn{2}{c}{ Right } & \multicolumn{1}{c}{ Left } \\
\hline Open & $20(13.1 \%)^{*}$ & $19(12.4 \%)^{* \#}$ & $24(24.2 \%)^{*}$ & $24(24.2 \%)^{* \#}$ & $87(17.3 \%)$ \\
\hline Closed & $124(81 \%)^{*}$ & $127(83 \%)^{* \#}$ & $71(71.7 \%)^{*}$ & $64(64.6 \%)^{* \#}$ & $386(76.6 \%)$ \\
\hline Meeting & $9(5.9 \%)^{*}$ & $6(3.9 \%)^{* \#}$ & $4(4 \%)^{*}$ & $10(10.1)^{* \#}$ & $29(5.7 \%)$ \\
\hline Unknown & $0(0 \%)$ & $1(0.7 \%)^{* \#}$ & $0(0 \%)$ & $1(1 \%)^{* \#}$ & $2(0.4 \%)$ \\
\hline Total & $153(100 \%)$ & $153(100 \%)$ & $99(100 \%)$ & $99(100 \%)$ & $504(100 \%)$ \\
\hline
\end{tabular}

* significant between sides

\# significant between sexes

left palm creases were significantly related between sexes. Table 2 shows the prevalence of palm crease types based on the relation of crease II and III. In males, the creases showed significant bilateral concordance. Table 3 shows the prevalence of subtypes of normal, Simian and Sydney creases according to the interaction between different types of crease II and III in the subjects. In the prevalence of different variations of I, II and III, most of the subjects had branched type of major palmar creases. Non-variant type was the second most common. (Table 4)

\section{DISCUSSION}

The current study showed that, based on the relation between crease I and II, closed palm crease was the most prevalent type and the type showed significant association between left and right palm.
Looking at the relation between II and III, normal type was the most abundant palm crease in both sexes in right as well as left palm. The prevalence of normal, Simian and Sydney creases showed significant association between left and right palm only in males.

This study attempted to identify and classify palm print types. Although the sample size doesn't permit generalising the results to the whole Nepalese population, this study has attempted to gather some information in this population. Photographic data collection has been found in this study to be quite unpredictable as blurry photographs due to movement of camera or subject during photography, or inappropriate auto focus tends to render data unusable.

Table 2. Prevalence of normal, Simian and Sydney crease types

\begin{tabular}{|c|c|c|c|c|c|}
\hline & \multicolumn{2}{|c|}{ Male } & \multicolumn{2}{|c|}{ Female } & \multirow[t]{2}{*}{ Total } \\
\hline & Right & Left & Right & Left & \\
\hline Normal crease & $135(88.2 \%)$ & $136(88.9 \%)^{*}$ & 88 (88.9\%) & $95(96 \%)$ & $454(90.1 \%)$ \\
\hline Simian & $15(9.8 \%)^{*}$ & $11(7.2 \%)^{*}$ & $10(10.1 \%)$ & $3(3 \%)$ & $39(7.7 \%)$ \\
\hline Sydney & $2(1.3 \%)^{*}$ & $4(2.6 \%)^{*}$ & $1(1 \%)$ & $0(0 \%)$ & $7(1.4 \%)$ \\
\hline Unknown & $1(0.7 \%)^{*}$ & $2(1.3 \%)^{*}$ & $0(0 \%)$ & $1(1 \%)$ & $4(0.8 \%)$ \\
\hline Total & $153(100 \%)$ & $153(100 \%)$ & $99(100 \%)$ & $99(100 \%)$ & $504(100 \%)$ \\
\hline
\end{tabular}


Table 3. Prevalence of subtypes of normal, Simian and Sydney creases

\begin{tabular}{|c|c|c|c|c|c|}
\hline \multirow[t]{2}{*}{ Crease } & \multicolumn{2}{|c|}{ Male } & \multicolumn{2}{|c|}{ Female } & \multirow[t]{2}{*}{ Total } \\
\hline & Right & Left & Right & Left & \\
\hline Normal 1 & $93(60.8 \%)$ & $95(62.1 \%)$ & $64(64.6 \%)$ & $67(67.7 \%)$ & $319(63.3 \%)$ \\
\hline Normal 2 & $42(27.5 \%)$ & $41(26.8 \%)$ & $24(24.2 \%)$ & $28(28.3 \%)$ & $135(26.8 \%)$ \\
\hline Simian 1 & $1(0.7 \%)$ & $0(0 \%)$ & $0(0 \%)$ & $0(0 \%)$ & $1(0.2 \%)$ \\
\hline Simian 2 & $2(0.7 \%)$ & $3(2 \%)$ & $2(2 \%)$ & $1(1 \%)$ & $8(1.6 \%)$ \\
\hline Simian 3 & $1(0.7 \%)$ & $2(1.3 \%)$ & $0(0 \%)$ & $0(0 \%)$ & $3(0.6 \%)$ \\
\hline Simian 4 & $10(6.5 \%)$ & $4(2.6 \%)$ & $8(8.1 \%)$ & $2(2 \%)$ & $24(4.8 \%)$ \\
\hline Simian 5 & $1(0.7 \%)$ & $2(1.3 \%)$ & $0(0 \%)$ & $0(0 \%)$ & $3(0.6 \%)$ \\
\hline Sydney 1 & $1(0.7 \%)$ & $3(2 \%)$ & $0(0 \%)$ & $0(0 \%)$ & $4(0.8 \%)$ \\
\hline Sydney 2 & $1(0.7 \%)$ & $1(0.7 \%)$ & $1(1 \%)$ & $0(0 \%)$ & $3(0.6 \%)$ \\
\hline Unknown & $1(0.7 \%)$ & $2(1.3 \%)$ & $0(0 \%)$ & $1(1 \%)$ & $4(0.8 \%)$ \\
\hline Total & $153(100 \%)$ & $153(100 \%)$ & $99(100 \%)$ & $99(100 \%)$ & $504(100 \%)$ \\
\hline
\end{tabular}

The prevalence of open, closed and meeting creases was similar to that found in Koreans by Park et al. (2010). ${ }^{3}$ The prevalence of normal, Simian and Sydney creases showed a similar trend to that seen in Koreans ${ }^{3}$ and Nigerians. ${ }^{20}$ In contrast to these studies, no Suwon crease was found in the current study. This could be because of the rarity of the crease type and the small sample in the current study as compared to the two.

Closed crease type was seen more in males while open crease type was seen more in females in the current study. This finding is similar to that found in the Korean population by Park et al.

On a smaller sample of normal and subjects with autism spectrum disorder in Netherlands, Bruin et al. (2014) $)^{21}$ found $2.1 \%$ and $4.2 \%$ Simian crease in left and right hands respectively in control group which was about double in the current study. They didn't find Sydney crease in left hand of cases as well as controls while the prevalence of Sydney crease on the right hand was similar to that seen in the current study. But, since the study didn't find any association between palm creases of cases and controls, the similarities and differences couldn't be compared with those groups.

Among some normal population, Down and Klinefelter subjects, Nazarabadi et al. (2015)22 found only $2.5 \%$ normal population with Simian crease which was almost thrice more commonly seen in the current study. Similarly, Wertelecki et al. $(1973)^{23}$ studied dermatoglyphics in patients of leukemia, first degree relatives and two control groups from America. They found Sydney and Simian crease in higher prevalence than that of the current study. The different genetic characteristics and geographical separation of genotypes could explain the difference of prevalence.

While comparing the prevalence of palm creases between 36 blind and 36 non blind subjects in Nigeria, Paul et al. (2016) ${ }^{24}$ found no Simian creases and minimal prevalence of Sydney creaseonly $0.6 \%$ in the female blind group while the prevalence of Suwon crease was much higher, accounting for $3.8 \%$ and $0.5 \%$ respectively in blind and non-blind males and $1.2 \%$ and $1 \%$ respectively in blind and non-blind females. This findings were 
Table 4. Prevalence of types of individual major palm creases

\begin{tabular}{|c|c|c|c|c|c|c|}
\hline \multirow{2}{*}{$\begin{array}{c}\text { S. } \\
\text { No. }\end{array}$} & \multirow[t]{2}{*}{ Type of crease } & \multicolumn{2}{|c|}{ Male } & \multicolumn{2}{|c|}{ Female } & \multirow[t]{2}{*}{ Total } \\
\hline & & Right & Left & Right & Left & \\
\hline \multirow[t]{8}{*}{ I } & Non-variant & $34(22.2 \%)$ & $39(25.5 \%)$ & $25(25.3 \%)$ & $18(18.2 \%)$ & $116(23 \%)$ \\
\hline & Branched & $72(47.1 \%)$ & $70(45.8 \%)$ & $45(45.5 \%)$ & $54(54.5 \%)$ & $241(47.8 \%)$ \\
\hline & Forked & $0(0 \%)$ & $1(0.7 \%)$ & $0(0 \%)$ & $1(1 \%)$ & $2(0.4 \%)$ \\
\hline & Accessory & $20(13.1 \%)$ & $12(7.8 \%)$ & $11(11.1 \%)$ & $6(6.1 \%)$ & $49(9.7 \%)$ \\
\hline & Broken & $26(17 \%)$ & $30(19.6 \%)$ & $18(18.2 \%)$ & $20(20.2 \%)$ & $94(18.7 \%)$ \\
\hline & Cascade & $1(0.7 \%)$ & $0(0 \%)$ & $0(0 \%)$ & $0(0 \%)$ & $1(0.2 \%)$ \\
\hline & Unknown & $0(0 \%)$ & $1(0.7 \%)$ & $0(0 \%)$ & $0(0 \%)$ & $1(0.2 \%)$ \\
\hline & Total & $153(100 \%)$ & $153(100 \%)$ & 99 (100\%) & $99(100 \%)$ & $504(100 \%)$ \\
\hline \multirow[t]{8}{*}{ II } & Non-variant & $75(49 \%)$ & $65(42.5 \%)$ & $40(40.4 \%)$ & $37(37.4 \%)$ & $217(43.1 \%)$ \\
\hline & Branched & $69(45.1 \%)$ & $82(53.6 \%)$ & $52(52.5 \%)$ & $57(57.6 \%)$ & $260(51.6 \%)$ \\
\hline & Forked & $2(1.3 \%)$ & $3(2 \%)$ & $3(3 \%)$ & $2(2 \%)$ & $10(2 \%)$ \\
\hline & Accessory & $4(2.6 \%)$ & $0(0 \%)$ & $1(1 \%)$ & $0(0 \%)$ & $5(1 \%)$ \\
\hline & Broken & $3(2 \%)$ & $1(0.7 \%)$ & $3(3 \%)$ & $2(2 \%)$ & $9(1.8 \%)$ \\
\hline & Cascade & $0(0 \%)$ & $0(0 \%)$ & $0(0 \%)$ & $0(0 \%)$ & $0(0 \%)$ \\
\hline & Unknown & $0(0 \%)$ & $2(1.3 \%)$ & $0(0 \%)$ & $1(1 \%)$ & $3(0.6 \%)$ \\
\hline & Total & $153(100 \%)$ & $153(100 \%)$ & $99(100 \%)$ & $99(100 \%)$ & $504(100 \%)$ \\
\hline \multirow[t]{8}{*}{ III } & Non-variant & $47(30.7 \%)$ & $37(24.2 \%)$ & $25(25.3 \%)$ & $23(23.2 \%)$ & $132(26.2 \%)$ \\
\hline & Branched & $83(54.2 \%)$ & $94(61.4 \%)$ & $56(56.6 \%)$ & $55(55.6 \%)$ & $288(57.1 \%)$ \\
\hline & Forked & $13(8.5 \%)$ & $10(6.5 \%)$ & $10(10.1 \%)$ & $13(13.1 \%)$ & $46(9.1 \%)$ \\
\hline & Accessory & $6(3.9 \%)$ & $7(4.6 \%)$ & $4(4 \%)$ & $3(3 \%)$ & $20(4 \%)$ \\
\hline & Broken & $1(0.7 \%)$ & $2(1.3 \%)$ & $1(1 \%)$ & $1(1 \%)$ & $5(1 \%)$ \\
\hline & Cascade & $3(2 \%)$ & $2(1.3 \%)$ & $3(3 \%)$ & $4(4 \%)$ & $12(2.4 \%)$ \\
\hline & Unknown & $0(0 \%)$ & $1(0.7 \%)$ & $0(0 \%)$ & $0(0 \%)$ & $1(0.2 \%)$ \\
\hline & Total & $153(100 \%)$ & $153(100 \%)$ & $99(100 \%)$ & $99(100 \%)$ & $504(100 \%)$ \\
\hline
\end{tabular}

in contrast to the results of the current study which could be due to the fact that the samples are taken from subjects of different geographical and genetic backgrounds. But in the comparative study done by Taura et al. (2014)25 between 109 epileptic and 109 healthy subjects from Hausas of Northern Nigeria, similar prevalence of normal, Simian and Sydney palm print types was seen as that found in the current study. About $47 \%$ of the Hausas carry haplogroup R1b Y-DNA. This genotype is mostly found in the western Europe and Asia with some presence in the central Asia too. ${ }^{26}$ The genetic overlap could explain some similarities in the genotypes and, consequently, palm crease types.

Further research could be done to link the patterns of palm prints to clinical conditions so that the associations can be defined. A larger sample would identify more crease types if they are present in the population and also be more representative. . 


\section{CONCLUSIONS}

This study presented data from 252 seemingly normal healthy subjects and found that most of them had the normal with no branching, that is normal 1, and closed crease types. Most of the individual major creases were seen to be branched type.

To cite this article: Ranjit N, Adhikari B, Shrestha R, Shrestha A, Bhandari R, Dhungel D, et al. Palm creases analysis in students and staff of a teaching hospital in Kathmandu. MJSBH. 2019;18(1):51-8.

Conflict of Interest: None declared

\section{REFERENCES}

1. Standring S. Gray's anatomy : the anatomical basis of clinical practice. 41st ed. Elsevier; 2016.

2. Biesecker LG, Aase JM, Clericuzio C, Gurrieri F, Temple IK, Toriello H. Defining Morphology: Hands and Feet. Am J Med Genet A. 2009 Jan;149A(1):93-127.

DOI: 10.1002/ajmg.a.32596

3. Park JS, Shin DS, Jung W, Chung MS. Improved analysis of palm creases. Anat Cell Biol. 2010;43(2): 169-77.

DOI: $10.5115 / \mathrm{acb} .2010 .43 .2 .169$

4. Duta N, Jain AK, Mardia KV. Matching of palmprints. Pattern Recognit Lett. 2002;23(4):477-85.

DOI: 10.1016/S0167-8655(01)00179-9

5. Kong A, Zhang D, Kamel M. A survey of palmprint recognition. Pattern Recognit. 2009;42(7):1408-18. DOI: 10.1016/j.patcog.2009.01.018

6. Lin C-L, Wang S-H, Cheng H-Y, Fan K-C, Hsu W-L, Lai C-R. Bimodal Biometric Verification Using the Fusion of Palmprint and Infrared Palm-Dorsum Vein Images. Liu L, editor. Sensors. 2015 Dec;15(12): 31339-61.

DOI: $10.3390 / \mathrm{s} 151229856$

7. Kanchana S, Balakrishnan G. Palm-Print Pattern Matching Based on Features Using Rabin-Karp for Person Identification. Sci World J. 2015;2015:382697.

DOI: $10.1155 / 2015 / 382697$

8. Reddy BRM, Sankar SG, E.T. R, Govulla S. A Comparative Study of Dermatoglyphics in Individuals with Normal Occlusions and Malocclusions. J Clin Diagn Res. 2013 Dec;7(12):3060-5.

DOI: $10.7860 / J C D R / 2013 / 7663.3853$

9. Forbes AP. Fingerprints and palm prints and palmar-flexion creases in gonadal dysgenesis, pseudohypoparathyroidism and Klinefelter's syndrome. N Engl J Med. 1964;270(24):1268-77.

DOI: 10.1056/NEJM196406112702402

10. Penrose LS. Medical significance of finger-prints and related phenomena. Br Med J. 1968;2(5601):321. DOI: $10.1136 / \mathrm{bmj} \cdot 2.5601 .321$

11. Sun L, Xue W, Li J, Zhou Z, Han W. Palm dermatoglyphs and interleukin-4 receptor polymorphisms in asthma. Biomed Rep. 2017 Jan;6(1):21-6.

DOI: $10.3892 /$ br.2016.803

12. Dar H, Schmidt R, Nitowsky HM. Palmar crease variants and their clinical significance: a study of newborns at risk. Pediatr Res. 1977;11(2):103.

DOI: 10.1203/00006450-197702000-00004

13. Jain R, Jain R, Gurunani K. Palmar flexion crease in male schizophrenics and their first degree relatives. Indian J Psychiatry. 1992;34(2):148-53. 
14. Hashim K, Thomas M. Sensitivity of palm print sign in prediction of difficult laryngoscopy in diabetes: A comparison with other airway indices. Indian J Anaesth. 2014;58(3):298-302.

DOI: $10.4103 / 0019-5049.135042$

15. Mahmoodpoor A, Soleimanpour H, Nia KS, Panahi JR, Afhami M, Golzari SE, et al. Sensitivity of Palm Print, Modified Mallampati Score and 3-3-2 Rule in Prediction of Difficult Intubation. Int J Prev Med. 2013 Sep;4(9):1063-9.

PMID: 24130949

16. Nadal JLY, Fernandez BG, Escobar IC, Black M, Rosenblatt WH. The palm print as a sensitive predictor of difficult laryngoscopy in diabetics. Acta Anaesthesiol Scand. 1998;42(2):199-203.

DOI: 10.1111/j.1399-6576.1998.tb05109.x

17. Kwiatkowska M, Jakutowicz T, Ciszek B, Czubak J. Can palmar creases serve as landmarks for the deeper neuro-vascular structures? Surg Radiol Anat. 2014;36(5):495-501.

DOI: $10.1007 / \mathrm{s} 00276-013-1211-4$

18. Wu X, Zhang D, Wang K, Huang B. Palmprint classification using principal lines. Pattern Recognit. 2004;37(10):1987-98.

DOI: 10.1016/j.patcog.2004.02.015

19. Sharma DK, Sharma V. Prevalences of Simian, Sydney and Suwon creases and their association with each other, body sides, handedness, sex and anomalies/diseases/syndromes in a population of Central India. Int J Morphol. 2011;29(3):1069-75.

DOI: $10.4067 /$ S0717-95022011000300069

20. Alhaji MM, Timbuak J, Umana UE, Tanko M. Palmar creases and handedness in Hausas of Northern Nigeria: a cross-sectional study. Asian J Biol Med Sci. 2015;1(2).

21. DeBruin IE, Graham JH, Louwerse A, Huizink AC. Mild Dermatoglyphic Deviations in Adolescents with Autism Spectrum Disorders and Average Intellectual Abilities as Compared to Typically Developing Boys. Autism Research and Treatment. 2014.

DOI: $10.1155 / 2014 / 968134$

22. Nazarabadi MH, Raoofian R, Abutorabi R, Hosseini HB. Dermatoglyphic assessment in Down and Klinefelter syndromes. Iran J Med Sci. 2015;32(2):105-9.

23. Wertelecki W, Plato GC, Fraumeni JF, Niswander JD. Dermatoglyphics in Leukemia. Pediatr Res. 1973 Jul 1;7:620.

DOI: $10.1203 / 00006450-197307000-00004$

24. Paul JN, Osunwoke EA, Paul CW. Prevalence of Simian, Suwon, and Sydney creases in acquired idiopathic blindness in some selected schools for the blind in Nigeria. Ann Bioanthropology. 2016;4(2): 75.

DOI: $10.4103 / 2315-7992.204679$

25. Taura AA, Taura MG, Adamu LH. Palmar Creases; A Comparative Study between Epilepsy Patients and Healthy Subjects among Hausas of Northern Nigeria. Am J Med Med Sci. 2014;4(5):175-9.

DOI: $10.5923 /$ j.ajmms.20140405.07

26. Hassan HY, Underhill PA, Cavalli-Sforza LL, Ibrahim ME. Y-chromosome variation among Sudanese: restricted gene flow, concordance with language, geography, and history. Am J Phys Anthropol Off Publ Am Assoc Phys Anthropol. 2008;137(3):316-23.

DOI: 10.1002/ajpa.20876 